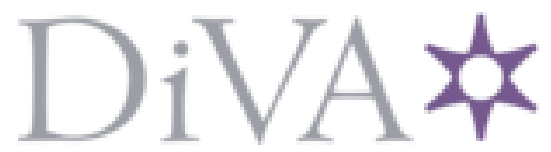

http://www.diva-portal.org

\title{
Postprint
}

This is the accepted version of a paper published in International Journal of Sexual Health. This paper has been peer-reviewed but does not include the final publisher proof-corrections or journal pagination.

Citation for the original published paper (version of record):

Areskoug-Josefsson, K., Juuso, P., Gard, G., Rolander, B., Larsson, A. (2016)

Health care students' attitudes toward addressing sexual health in their future profession:

Validity and reliability of a questionnaire.

International Journal of Sexual Health, 28(3): 243-250

http://dx.doi.org/10.1080/19317611.2016.1199453

Access to the published version may require subscription.

N.B. When citing this work, cite the original published paper.

Permanent link to this version:

http://urn.kb.se/resolve?urn=urn:nbn:se:hj:diva-31563 


\section{Health care students' attitudes towards addressing sexual health in their future profession: Validity and reliability of a questionnaire}

Objectives: To test the reliability and validity of the Students' Attitudes Towards Addressing Sexual Health questionnaire (SA-SH), measuring students' attitudes towards addressing sexual health in their future professions.

Method: A cross-sectional online survey (22 items) were distributed to 186 nursing, occupational therapy and physiotherapy students in Sweden, April 2015. Validity and reliability were tested.

Results: The construct validity analysis led to three major factors: present feelings of comfortableness, future working environment and fear of negative influence on future patient relations. The construct validity, internal consistency reliability and intrarater reliability showed good results.

Conclusion: The SA-SH is valid and reliable.

\section{Introduction}

Earlier research has shown that patients with chronic conditions often rate their sexual health as important, but neglected by health care professionals (Bitzer, Platano, Tschudin, \& Alder, 2007; Papaharitou et al., 2008), despite research showing that health care providers can moderate the sexual expression of persons suffering from chronic disease (O'Dea, Shuttleworth, \& Wedgwood, 2012), and the patients have a right to have eventual sexual problems thoughtfully identified and addressed (Krebs, 2007). Maintaining professional boundaries is essential when working with sexual health, and students in health care professions need to have sufficient knowledge of how to work with sexual health and to feel confident that they are still upholding professional boundaries, despite the sensitive subject 
and the hands-on practice that nursing and rehabilitation often include (Soundy, Stubbs, Jenkins, \& Cooper, 2013). There are several reasons that health care professionals avoid communicating with their patients about sexual health, including underestimation of the prevalence of decreased sexual health, embarrassment, and personal discomfort, together with lack of time, privacy, and competence (Haboubi \& Lincoln, 2003; Helland, Garratt, Kjeken, Kvien, \& Dagfinrud, 2013; Kirana et al., 2009; Krebs, 2007; McGrath \& Lynch, 2014;

Reynolds \& Magnan, 2005). Gender, patient's age, personal values, and experiences influence students' attitudes toward sexual issues, and negative attitudes can impede effective sexual health consultations (Areskoug-Josefsson \& Gard, 2015; Krebs, 2007). Awareness has to be raised of the students' own values and prejudices and knowledge of their attitudes towards working with sexual health, in order to address those issues with increased knowledge and competence (Krebs, 2007; Papaharitou et al., 2008; Sung, Huang, \& Lin, 2015).

Understanding of one's own personal sexual attitudes and previous communicative training are useful for health care professionals when addressing sexual issues with patients (Krebs, 2007; McGrath \& Lynch, 2014; Sung et al., 2015; Tsimtsiou et al., 2006). Those issues address the importance of ensuring that future health care professionals have sufficient knowledge and competence concerning sexual health.

To investigate the attitudes of health care students towards working with sexual health in their future professions, there was a need to develop a new questionnaire. There are questionnaires used to explore university students' attitudes concerning sexuality, sexual preferences, and sexual activities as such, but they do not cover attitudes towards working with sexual health promotion (Nemcic et al., 2005; Reynolds \& Magnan, 2005). There are also questionnaires aiming to explore the views of health professionals concerning communication and support to improve sexual health issues, but they are not appropriate for health professional students lacking work experience (Haboubi \& Lincoln, 2003; Jaarsma et al., 2010; Kim, Kang, \& Kim, 
2011). There are several questionnaires aiming to investigate health care professionals' knowledge and ways of dealing with sexual health care issues for specific patient groups, but those questionnaires are specific regarding disease, age, gender, or sexual orientation and are not appropriate for exploring attitudes of health care professional students about the topic of working with sexual health in general in their future professions.

\begin{abstract}
Aim
The aim of the study was to test the reliability, face validity, and construct validity of a Swedish questionnaire, Students’ Attitudes Towards Addressing Sexual Health (SA-SH), measuring students' attitudes towards working with sexual health in their future professions.
\end{abstract}

\title{
Method
}

A cross-sectional quantitative study with an online survey distributed to nursing, occupational therapy, and physiotherapy students was performed at a Swedish university in 2015 . The regional ethical board received a complete ethical approval application prior to the study, and responded that the study did not demand ethical approval by the regional ethical board, but that the ethical board did not find any ethical problems with the project (2015/35-31Ö).

\section{$\underline{\text { Subjects }}$}

All students within the mentioned professions were invited to participate in the study via email, through information on the homepage for each course and oral information given in class. The students also received information regarding the study on the first page of the survey; they were informed that participation was voluntary and that answering the survey constituted informed consent. 


\section{The survey}

The questionnaire SA-SH (Appendix 1) was used, together with background questions concerning gender, age, semester, and future profession. To develop a questionnaire suitable for students in health care professions, a literature review and focus groups were performed prior to the study, to collect relevant published as well as experience-based knowledge. The questionnaire developed is based on the results from prior focus group interviews (AreskougJosefsson \& Gard, 2015). In the developmental process the phrasing of the questions was carefully considered to include both positive and negative attitudes. The questionnaire consisted of 22 items measured using a 5-step Likert scale (disagree, partly disagree, partly agree, agree, strongly agree).

\section{$\underline{\text { Data collection }}$}

All students were given a short ( 5 min) explanation of the study by one of the researchers, in a regular class, in an online class, or via an informational video on their course homepage, prior to receiving invitational e-mails about the study. The invitational e-mail included information about the study and stated that participation in the study was voluntary and would not in any way affect their academic results. A link to the online survey was included in the e-mail. After two weeks a reminder e-mail was sent out to the students. The online survey was performed with EvaSys Education Survey Automation Suite V6.0 ( 2001-2014 Electric Paper Evaluation Systems GmbH in Lüneburg Germany).

The first 100 respondents were invited to answer the questionnaire a second time, in a reliability test of the questionnaire (test-retest). The recommended number of respondents in test-retest is 50 , and therefore, the estimation of a response rate of $50 \%$ would lead to a sufficient number of respondents (Hopkins, 2000). The participating students did not receive any reimbursement for their participation. 
$\underline{\text { Analysis }}$

The analysis of the data was performed both on the complete questionnaire and on the major factors that emerged according to the factor analysis.

Face validity results were analysed by the present authors, together with the face validity participants (DeVon et al., 2007). Construct validity was analysed with explorative factor analysis with principal component analysis (rotated method) (Polit \& Beck, 2006).

The data were analysed with descriptive statistics. Intrarater reliability was analysed with Elisabeth Svensson's method for test-retest, both on item level and on the factors found in the construct validity test. This method was chosen for the test-retest analysis because it provides the ability to detect both systematic and individual estimation errors (Svensson, 2012). The use of Elisabeth Svensson's method on the found factors was performed by using the medians of each item of the factors. The significant level was set at $\mathrm{p}<0.05$. A statistically significant difference was found when the confidence intervals did not enclose zero for relative position (RP) and relative concentration (RC). RP and RC are measured with a coefficient between -1 and 1 , where a coefficient close to zero is desirable. Individual variability (RV) which is different from zero is a sign of individual variation that cannot be explained by the systematic disagreement.

The relative position measures whether there has been a systematic change in the answering of the item. The relative concentration describes whether there is a change in how the measurements are concentrated on the scale for the items. The relative rank variance shows individual variability with low values describing homogeneous change patterns within the group and high values describing heterogeneous change patterns. High values of RV indicate that the current question can be interpreted in several ways, and/or that the scale is poor and that coincidence is steering responses (Svensson, 2001). The results for the major factors 
show homogeneous change patterns with very low systematic changes in the answers and very low individual variability, thus showing robust intrarater reliability of the questionnaire and for the major factors according to the Elisabeth Svensson method.

Internal consistency reliability was analysed with Cronbach's alpha (DeVon et al., 2007) for the factors with the highest loadings. Descriptive statistics, Cronbach's alpha, and explorative factor analysis were performed using SPSS version 22 (IBM Corp, Armonk, New York, USA).

\section{Results}

The questionnaire was sent out to 419 nursing students, 193 physiotherapy students, and 136 occupational therapy students. The response rate was very low among students of all of the included health care professions: occupational therapy $32 \%$, nursing $23 \%$, and physiotherapy $23 \%$. The responding students were, however, quite equally divided among semesters, gender, and age, compared to the whole group of 186 participants.

The retest group consisted of 53 participants (response rate 53\%).

\section{Validity}

The questionnaire was tested for face validity in two student groups (5 students in each group, one group with nursing students and one group with physiotherapy students) prior to the start of the study. The results of the face validity test showed that the students acknowledged the importance of the theme. They considered sexual health as a new field in their professions and described a lack of education in sexual health, but despite this, they considered the questionnaire relevant. The face validity test led to minor alterations in the wording of two items in the questionnaire. 
Construct validity was measured with explorative factor analysis with principal component as extraction method and for factor rotations were Varimax with Kaiser normalisation was used. Items with high factor loadings define each dimension. We considered that, to be a clinically meaningful item in one of these factors, each item had to have a loading over .50 in accordance with Hair et al. (Hair, Anderson, Tatham, \& Black, 1998). Each item was also, to be clinically meaningful, referred to the factor in which it had the highest loading; see Table 2. There were three meaningful factors following logical reasoning concerning the content of the items, which could be seen with a scree plot which was used to determine the optimal number of factors. These factors showed a total variance explained for factor 1 of $37 \%$, for factor 2 of $11 \%$, and for factor 3 of $8 \%$. The three major factors are presented in Table 1 , together with the explorative factor analysis of the retest group with a total variance explained for factor 1 of $38 \%$, factor 2 of $13 \%$, and factor 3 of $10 \%$. The correlation between factor 1 and factor 2 was (rs=-0.04), between factor 1 and factor $3(\mathrm{rs}=0.001)$ and for factor 2 and factor 3 (rs=0.07).

Table 1 about here

\section{$\underline{\text { Reliability }}$}

The internal consistency reliability gave a Cronbach's alpha of 0.61 , with variance of 0.54 0.67 if the tested item was deleted. Cronbach's alpha values for the retest group gave a Cronbach's alpha of 0.71 , with variance of $0.65-0.75$ if the tested item was deleted.

According to analysis with the Elisabeth Svensson method, there aren't systematic changes of positions on the scale of assessments, RP, or how the assessments are concentrated on categories of the scale, RC (Svensson, 2001). There are tendencies towards rating lower at re- 
test for the item "I believe that future patients may feel embarrassed if I bring up sexual questions" and the item "I believe that I will have too much to do in my future profession to have time to deal with sexual issues." There is also a tendency for a higher rating for the item "I am afraid that my future colleagues would feel uncomfortable dealing with questions regarding patients' sexual health." There is a high level of additional individual variation (percentage agreement) in several questions in test-retest, but not systematic disagreement (see Table 2), which indicates that the test situation was stable (Svensson, 2001).

Table 2 about here

\section{Discussion}

The face validity and the construct validity of the SA-SH are good (DeVon et al., 2007; Polit $\&$ Beck, 2006) and indicate that the questionnaire could be used in further research and educational interventions. The major factors in the factor analysis were feelings of comfortableness, future working environment, and fear of negative influence on future patient relations. Working with sexual health thus depends not only on personal attitudes of the students, but also on the working environment. According to Sung (Sung et al., 2015) education about positive attitudes towards sexuality should be included in sexual health interventions for students. Strategies regarding how to handle a working environment that is negative towards working with sexual health promotion should be addressed when educating future health care professionals in sexual health. The factors from the factor analysis could be useful as a base when planning interventions and education to improve students' ability to work with sexual health in their future professions, and as a guide for conceptual objectives. Some items were not included in the major factors but were still considered important by the 
face validity test and earlier research in the field; however, there might be further improvement in the questionnaire if those items were reworded and retested.

The internal consistency reliability shows stability in good to acceptable reliability according to Cronbach's alpha (Kimberlin \& Winterstein, 2008; Polit \& Beck, 2006). For the major factors from the explorative factor analysis with principal component, the three major factors show excellent to good reliability. The first part of the questionnaire (items 1-8) included the major factor with the highest Cronbach's alpha. The first part concerns the students' present situation and attitudes towards working with sexual health. This part of the questionnaire might be more easily answered than the following parts, even if this has not been the described by the face validity groups. Questions regarding future situations and collegial cooperation might be more difficult to answer, since the students lack experience from working in their future professions. This must be acknowledged when using the questionnaire in future research or education.

Test-retest is not commonly used to evaluate intrarater reliability in sexuality related questionnaires (Fisher, Davis, Yarber, \& Davis, 2013). According to Elisabeth Svensson's method, the test-retest shows sensitivity to disturbing factors, when there is no other systematic disagreement present (Svensson, 2012). Thus, the novelty of the subject sexual health within the professions might be a disturbing factor influencing test-retest if a developmental process takes place during the two-week test interval. In this process the students might reflect on how sexual health could be a part of their future professions, which could reflect the differences in the answers. It is possible that another test-retest of reliability among participants with work experience would lead to a different result, and the questionnaire should be designed and tested in this group as an additional research project. A suggestion for future reliability testing of the questionnaire would be to start with an introduction of the topic sexual health two weeks prior to the start of test-retest, to give the 
participants time to reflect on their answers and on the topic, and thus start the developmental process that has been indicated by the test-retest results and the earlier qualitative focus group study. The emerging themes from the focus groups showed that the student's considered the issue of sexual health to be a new professional challenge, affected by personal life experiences, demanding good communication skills and perceptive patient understanding, influenced by environmental factors, and an area where they needed to develop competence (Areskoug-Josefsson \& Gard, 2015). The novelty of including sexual health in their future professions was also brought forward by the students participating in the face validity groups. This reflection from the face validity groups could be used as a discussion point in future research, when deciding on how the reliability test with test-retest should be optimally performed. There is also research supporting a prior introduction to the topic in order to explore the students' own values, attitudes, and perceptions of patients' sexual health care issues in a developmental process to enhance their ability to deal with sexual health care issues in their future professions (Sung et al., 2015; Tsimtsiou et al., 2006). If the students feel unfamiliar with the topic, they may answer according to what they believe they are expected to answer. This conclusion adds substance to the suggestion that the students need time to reflect and analyse their own attitudes and knowledge of sexual health issues before doing baseline tests prior to an educational intervention within the field of sexual health.

The format of the study could be a reason for the low response rate, since e-mail surveys often get lower response rates than paper surveys (Nulty, 2008). If the students had been asked to complete the questionnaire during class, it is likely that the study would have had a higher response rate. However, a paper survey might have resulted in the students feeling obliged to participate if their professor had handed out the questionnaire, which would have been unethical. Survey responders in general are more likely to be interested in the subject than non-responders (Porter \& Umbach, 2006). Interest in the subject could be of importance, 
since sexual health is a field often neglected within care and rehabilitation. The students may also be less aware of the existing professional role within sexual health, since education in the field of sexual health is often limited (Wazakili, Mpofu, \& Devlieger, 2009), which may affect their interest towards participation in the study. The participants did not receive any reward for their participation, which may have decreased their willingness to participate, but there is also research showing that this does not have a major effect on response rates (Porter \& Umbach, 2006). There is a possibility that the response rates would have increased if the questionnaire had been sent out by paper instead of by e-mail (Porter \& Umbach, 2006; Sax, Gilmartin, \& Bryant, 2003). Face-to-face administration often increases response rate, and the information sessions prior to the study were considered to be of assistance in improving response rates. Response rates are discussed by Nulty (Nulty, 2008), and the response rate of our study would be considered as acceptable under liberal conditions, considering the sample size of each professional group, even if those who responded were systematically different from those who did not. There is a possibility that the participants in the survey represent students with a specific interest in sexual health, and this bias could have affected the results. To further ensure that the responses from the questionnaire are correct, they have been compared to a prior qualitative study as well as to earlier research findings (AreskougJosefsson \& Gard, 2015).

The intention of the questionnaire is to explore attitudes prior to planning educational interventions and to use it to assess educational interventions within the field of sexual health. It might useful to further develop the SA-SH for future use for health care professionals as well, since there is a lack of stable intrarater questionnaires within the field of sexual health (Fisher et al., 2013). Since the questionnaire is valid and reliable for students in nursing, occupational therapy and physiotherapy, it is probable that the questionnaire could be used to investigate attitudes towards sexual health for students in other healthcare professions as well. 


\section{Conclusion}

The questionnaire showed stable face validity. The construct validity was robust and showed stability in the explorative factor analysis.

The questionnaire has good internal consistency reliability and intrarater reliability. Testretest is preferably performed by using an introduction to the topic of sexual health related to the students' future professional roles prior to the test, in order to start the developmental process which takes place when introducing a theme novel to them in their professional education.

\section{Acknowledgements}

Futurum, Academy for Health and Care, Jönköping County Council, Jönköping, and Per

Westlings Foundation, Lund, funded the research project.

\section{References}

Areskoug-Josefsson, Kristina, \& Gard, Gunvor. (2015). Sexual Health as a Part of Physiotherapy: The Voices of Physiotherapy Students. Sexuality and Disability, 1-20. doi: 10.1007/s11195-0159403-y

Bitzer, J., Platano, G., Tschudin, S., \& Alder, J. (2007). Sexual counseling for women in the context of physical diseases: a teaching model for physicians. J Sex Med, 4(1), 29-37. doi: JSM395 [pii] 10.1111/j.1743-6109.2006.00395.x

DeVon, H. A., Block, M. E., Moyle-Wright, P., Ernst, D. M., Hayden, S. J., Lazzara, D. J., . . KostasPolston, E. (2007). A psychometric toolbox for testing validity and reliability. Journal of nursing scholarship : an official publication of Sigma Theta Tau International Honor Society of Nursing / Sigma Theta Tau, 39(2), 155-164. doi: 10.1111/j.1547-5069.2007.00161.x

Fisher, T.D., Davis, C.M., Yarber, W.L., \& Davis, S.L. (2013). Handbook of Sexuality-Related Measures: Taylor \& Francis.

Haboubi, N. H., \& Lincoln, N. (2003). Views of health professionals on discussing sexual issues with patients. Disability and Rehabilitation, 25(6), 291-296. doi: 306T2HVP9V2UGU03 [pii]

Hair, J., Anderson, R., Tatham, R., \& Black, W. (Eds.). (1998). Multivaliate data analysis. New Jersey: Prentice Hall.

Helland, Y., Garratt, A., Kjeken, I., Kvien, T., \& Dagfinrud, H. (2013). Current practice and barriers to the management of sexual issues in rheumatology: results of a survey of health professionals. Scandinavian Journal of Rheumatology, 42(1), 20-26. doi: 10.3109/03009742.2012.709274 
Hopkins, W. G. (2000). Measures of reliability in sports medicine and science. Sports Med, 30(1), 115.

Jaarsma, T., Stromberg, A., Fridlund, B., De Geest, S., Martensson, J., Moons, P., . . group, Unite research. (2010). Sexual counselling of cardiac patients: nurses' perception of practice, responsibility and confidence. Eur J Cardiovasc Nurs, 9(1), 24-29. doi: 10.1016/j.ejcnurse.2009.11.003

Kim, S., Kang, H. S., \& Kim, J. H. (2011). A sexual health care attitude scale for nurses: development and psychometric evaluation. Int J Nurs Stud, 48(12), 1522-1532. doi: 10.1016/j.ijnurstu.2011.06.008

Kimberlin, C. L., \& Winterstein, A. G. (2008). Validity and reliability of measurement instruments used in research. American journal of health-system pharmacy: AJHP : official journal of the American Society of Health-System Pharmacists, 65(23), 2276-2284. doi: 10.2146/ajhp070364

Kirana, P. S., Papaharitou, S., Athanasiadis, L., Nakopoulou, E., Salpiggidis, G., Moysidis, K., ... Hatzichristou, D. (2009). A conceptual framework for the evolution of sexual medicine and a model for the development of alternative sexual health services: 10-year experience of the center for sexual and reproductive health. J Sex Med, 6(9), 2405-2416. doi: 10.1111/j.1743$6109.2009 .01320 . x$

Krebs, L. U. (2007). Sexual assessment: research and clinical. Nurs Clin North Am, 42(4), 515-529; v. doi: 10.1016/j.cnur.2007.07.004

McGrath, M., \& Lynch, E. (2014). Occupational therapists' perspectives on addressing sexual concerns of older adults in the context of rehabilitation. Disabil Rehabil, 36(8), 651-657. doi: 10.3109/09638288.2013.805823

Nemcic, N., Novak, S., Maric, L., Novosel, I., Kronja, O., Hren, D., . . Marusic, M. (2005). Development and validation of questionnaire measuring attitudes towards sexual health among university students. Croat Med J, 46(1), 52-57.

Nulty, D.D. (2008). The adequacy of response rates to online and paper surveys: what can be done? Assessment \& Evaluation in Higher Education, 33(3), 301-314.

O'Dea, ShaneM, Shuttleworth, RussellP, \& Wedgwood, Nikki. (2012). Disability, Doctors and Sexuality: Do Healthcare Providers Influence the Sexual Wellbeing of People Living with a Neuromuscular Disorder? Sexuality and Disability, 30(2), 171-185. doi: 10.1007/s11195-0119235-3

Papaharitou, S., Nakopoulou, E., Moraitou, M., Tsimtsiou, Z., Konstantinidou, E., \& Hatzichristou, D. (2008). Exploring sexual attitudes of students in health professions. J Sex Med, 5(6), 13081316. doi: $10.1111 /$ j.1743-6109.2008.00826.x

Polit, D.F., \& Beck, C.T. (2006). Essentials of Nursing Research. Methods, Appraisal and Utilization (6 ed.). Philadelphia: Lippingcott.

Porter, S.R., \& Umbach, P.D. (2006). Student survey response rates across institutions: Why do they vary? Research in Higher Education, 47(2), 230-247. doi: 10.1007/s11162-005-8887-1

Reynolds, K. E., \& Magnan, M. A. (2005). Nursing attitudes and beliefs toward human sexuality: collaborative research promoting evidence-based practice. Clin Nurse Spec, 19(5), 255-259.

Sax, L.J., Gilmartin, S.K., \& Bryant, A.N. (2003). Assessing responserate and nonresponse bias in web and paper surveys. Research in Higher Education, 44(4), 409-432.

Soundy, A., Stubbs, B., Jenkins, S., \& Cooper, I. (2013). Sexual professional boundaries perceived by undergraduate and graduate physiotherapists: a cross sectional survey. Physiotherapy, 99(4), 298-304. doi: 10.1016/j.physio.2012.12.005

Sung, Su-Ching, Huang, Hui-Chi, \& Lin, Mei-Hsiang. (2015). Relationship Between the Knowledge, Attitude, and Self-Efficacy on Sexual Health Care for Nursing Students. Journal of Professional Nursing, 31(3), 254-261. doi: http://dx.doi.org/10.1016/j.profnurs.2014.11.001

Svensson, E. (2001). Guidelines to statistical evaluation of data from rating scales and questionnaires. J Rehabil Med, 33(1), 47-48. 
Svensson, E. (2012). Different ranking approaches defining association and agreement measures of paired ordinal data. Stat Med, 31(26), 3104-3117. doi: 10.1002/sim.5382

10.1002/sim.5382. Epub 2012 Jun 19.

Tsimtsiou, Z., Hatzimouratidis, K., Nakopoulou, E., Kyrana, E., Salpigidis, G., \& Hatzichristou, D. (2006). Predictors of physicians' involvement in addressing sexual health issues. J Sex Med, 3(4), 583-588. doi: 10.1111/j.1743-6109.2006.00271.x

Wazakili, M., Mpofu, R., \& Devlieger, P. (2009). Should issues of sexuality and HIV and AIDS be a rehabilitation concern? The voices of young South Africans with physical disabilities.

Disability \& Rehabilitation, 31(1), 32-41. doi: 10.1080/09638280802280619 
Appendix 1.

Students' Attitudes Towards Addressing Sexual Health (SA-SH)

1. I feel comfortable about informing future patients about sexual health. $(\mathrm{m}=3.4, \mathrm{sd}=1.1)$.

2. I feel comfortable about initiating a conversation regarding sexual health with future patients. $(\mathrm{m}=3.1, \mathrm{sd}=1.1)$.

3. I feel comfortable about discussing sexual health with future patients. $(m=3.4, s d=1.2)$.

4. I feel comfortable about discussing sexual health issues with future patients regardless of their sex. $(\mathrm{m}=3.4, \mathrm{sd}=1.2)$.

5. I feel comfortable about discussing sexual health issues with future patients regardless of their age. $(\mathrm{m}=3.2, \mathrm{sd}=1.2)$.

6. I feel comfortable about discussing sexual health issues with future patients regardless of their cultural background. $(\mathrm{m}=3.2, \mathrm{sd}=1.3)$.

7. I feel comfortable about discussing sexual health issues with future patients regardless of their sexual orientation. $(\mathrm{m}=3.7, \mathrm{sd}=1.2)$.

8. I feel comfortable about discussing specific sexual activities with future patients. $(\mathrm{m}=2.7$, $\mathrm{sd}=1.2)$.

9. I am unprepared to talk about sexual health with future patients. $(m=3.4, s d=1.2)$

10. I believe that I might feel embarrassed if future patients talk about sexual issues. $(\mathrm{m}=2.3$, $\mathrm{sd}=1.0)$.

11. I believe that future patients might feel embarrassed if I bring up sexual issues. $(m=3.4$, $\mathrm{sd}=0.8)$. 
12. I am afraid that future patients might feel uneasy if I talk about sexual issues. $(m=3.1$, $\mathrm{sd}=1.0)$.

13. I am afraid that conversations regarding sexual health might create a distance between me and the patients. $(\mathrm{m}=2.5, \mathrm{sd}=1.1)$.

14. I believe that I will have too much to do in my future profession to have time to handle sexual issues. $(\mathrm{m}=2.7, \mathrm{sd}=1.2)$.

15. I will take time to deal with patients' sexual issues in my future profession. $(m=3.1$, $\mathrm{sd}=1.0)$.

16. I am afraid that my future colleagues would feel uneasy if I brought up sexual issues with patients. $(\mathrm{m}=2.4, \mathrm{sd}=1.1)$.

17. I am afraid that my future colleagues would feel uncomfortable in dealing with questions regarding patients' sexual health. $(\mathrm{m}=2.8, \mathrm{sd}=1.0)$.

18. I believe that my future colleagues will be reluctant to talk about sexual issues. $(m=2.6$, $\mathrm{sd}=1.0)$.

19. In my education I have been educated about sexual health. $(\mathrm{m}=2.2, \mathrm{sd}=1.3)$.

20. I think that I as a student need to get basic knowledge about sexual health in my education. $(\mathrm{m}=4.2, \mathrm{sd}=1.1)$.

21. I have sufficient competence to talk about sexual health with my future patients. $(\mathrm{m}=2.3$, $\mathrm{sd}=1.1)$.

22. I think that I need to be trained to talk about sexual health in my education. $(m=4.1$, $\mathrm{sd}=1.1)$.

All questions are answered on a Likert scale with 5 options: disagree, partly disagree, partly agree, agree, strongly agree. 
$(m=$ mean, $s d=$ standard deviation $)$ 
Table 1. Internal consistency reliability and percentage agreement of the three major factors

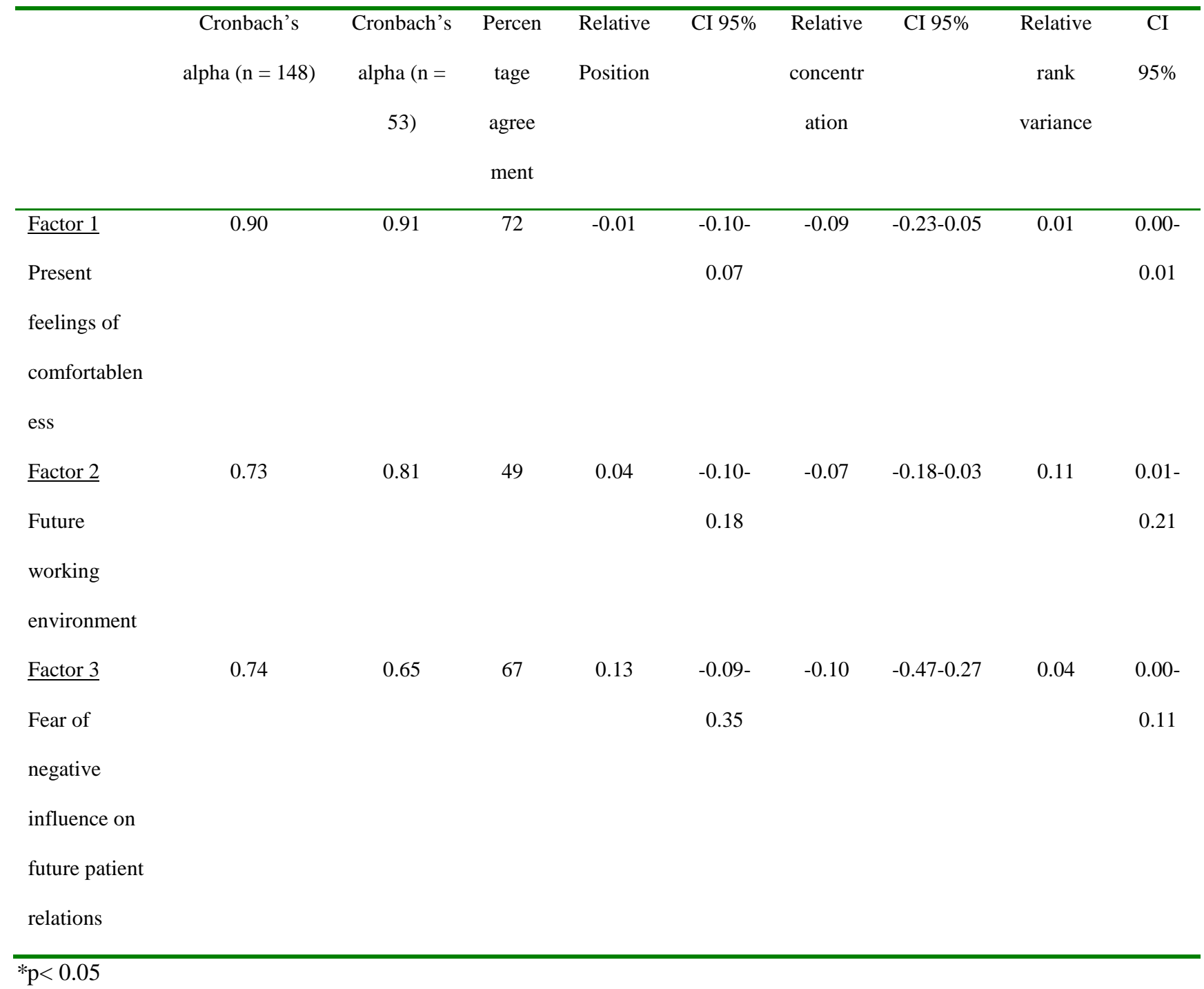


Table 2. Factor value, percentage agreement, relative position, relative concentration, and relative rank variation of the items in each factor

\begin{tabular}{|c|c|c|c|c|c|c|c|c|}
\hline Label & $\begin{array}{c}\text { Facto } \\
\text { r } \\
\text { value }\end{array}$ & $\begin{array}{l}\text { Percent } \\
\text { age } \\
\text { agree- } \\
\text { ment }\end{array}$ & $\begin{array}{l}\text { Relativ } \\
\mathrm{e} \\
\text { positio } \\
\mathrm{n}\end{array}$ & CI $95 \%$ & $\begin{array}{l}\text { Relativ } \\
\text { e } \\
\text { concent } \\
\text { ration }\end{array}$ & CI 95\% & $\begin{array}{c}\text { Relative } \\
\text { rank } \\
\text { variance }\end{array}$ & CI $95 \%$ \\
\hline \multicolumn{9}{|l|}{ Factor 1} \\
\hline $\begin{array}{l}\text { 1.I feel comfortable about } \\
\text { informing future patients }\end{array}$ & 0.84 & 57 & -0.4 & $\begin{array}{l}-0.13- \\
0.06\end{array}$ & 0.01 & $\begin{array}{c}-0.13- \\
0.16\end{array}$ & 0.02 & $0.00-0.05$ \\
\hline about sexual health & & & & & & & & \\
\hline $\begin{array}{l}\text { 2.I feel comfortable about } \\
\text { initiating a conversation }\end{array}$ & 0.91 & 62 & -0.05 & $\begin{array}{l}-0.15- \\
0.05\end{array}$ & -0.10 & $\begin{array}{l}-0.25- \\
0.05\end{array}$ & 0.02 & $0.00-0.05$ \\
\hline $\begin{array}{l}\text { regarding sexual health } \\
\text { with future patients }\end{array}$ & \multicolumn{7}{|c|}{ regarding sexual health } & \\
\hline $\begin{array}{l}\text { 3.I feel comfortable about } \\
\text { discussing sexual health }\end{array}$ & 0.89 & 51 & -0.03 & $\begin{array}{c}-0.14- \\
0.09\end{array}$ & -0.07 & $\begin{array}{l}-0.20- \\
0.06\end{array}$ & 0.08 & $0.00-0.18$ \\
\hline \multicolumn{9}{|l|}{ with future patients } \\
\hline $\begin{array}{l}\text { 4.I feel comfortable about } \\
\text { discussing sexual health }\end{array}$ & 0.84 & 55 & 0.00 & $\begin{array}{c}-0.10- \\
0.09\end{array}$ & 0.00 & $\begin{array}{c}-0.14- \\
0.15\end{array}$ & 0.03 & $0.00-0.06$ \\
\hline issues with future patients & & & & & & & & \\
\hline regardless of their sex & & & & & & & & \\
\hline $\begin{array}{l}\text { 5.I feel comfortable about } \\
\text { discussing sexual health }\end{array}$ & 0.88 & 54 & 0.01 & $\begin{array}{l}-0.09- \\
0.11\end{array}$ & 0.01 & $\begin{array}{c}-0.14- \\
0.16\end{array}$ & 0.04 & $0.00-0.08$ \\
\hline issues with future patients & & & & & & & & \\
\hline regardless of their age & & & & & & & & \\
\hline 6.I feel comfortable about & 0.82 & 50 & -0.13 & $-0.22-$ & 0.03 & $-0.15-$ & 0.03 & $0.00-0.07$ \\
\hline discussing sexual health & & & & -0.03 & & 0.22 & & \\
\hline issues with future patients & & & & & & & & \\
\hline
\end{tabular}




\begin{tabular}{|c|c|c|c|c|c|c|c|c|}
\hline \multicolumn{9}{|l|}{ background } \\
\hline $\begin{array}{l}\text { 7.I feel comfortable about } \\
\text { discussing sexual health }\end{array}$ & 0.89 & 60 & -0.07 & $\begin{array}{l}-0.14- \\
0.01\end{array}$ & 0.03 & $\begin{array}{l}-0.10- \\
0.17\end{array}$ & 0.01 & $0.00-0.03$ \\
\hline \multicolumn{9}{|l|}{ issues with future patients } \\
\hline \multicolumn{9}{|l|}{ regardless of their sexual } \\
\hline \multicolumn{9}{|l|}{ orientation } \\
\hline 8.I feel comfortable about & 0.82 & 51 & -0.03 & $-0.14-$ & -0.07 & $-0.20-$ & 0.08 & $0.00-0.18$ \\
\hline discussing specific sexual & & & & 0.09 & & 0.06 & & \\
\hline \multicolumn{9}{|l|}{ activities with future } \\
\hline patients & & & & & & & & \\
\hline
\end{tabular}

Factor 2

have too much to do in my

future profession to have

time to handle sexual

issues

17.I am afraid that my

future colleagues would

feel uncomfortable in

dealing with questions

regarding patients' sexual

health

18.I believe that my future

colleagues will be

reluctant to talk about

sexual issues
0.64

$39-0.15$

$0.03-\quad 0.02$

0.27 *

$-0.15-$

0.05

0.01-0.09

0.19

$\begin{array}{lll}0.64 & 35 & 0.00\end{array}$

$-0.15-\quad-0.08$

$-0.23-$

$0.15 \quad 0.01-0.28$

0.15

0.07

$\begin{array}{llllllll}0.66 \quad 44 & 0.13 \quad-0.02- & -0.09 & -0.24- & 0.17 & 0.02-0.32 \\ & & 0.28 & & 0.05 & & \end{array}$

Factor 3 


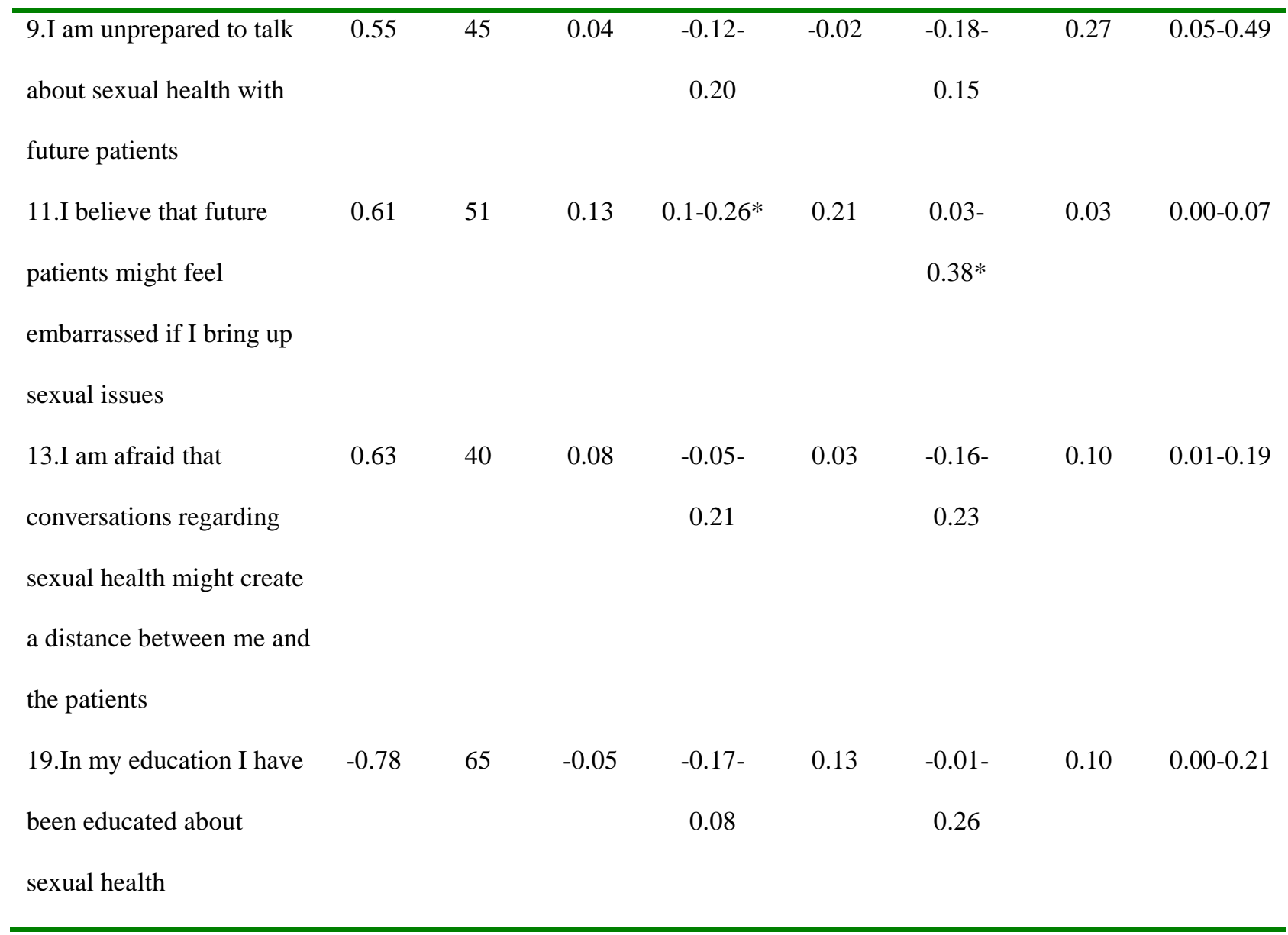

${ }^{*} \mathrm{Pp}<0.05$ 